\title{
Further biochemical characterization of Mycobacterium leprae laminin-binding proteins
}

M.A.M. Marques ${ }^{1}$, S. Mahapatra ${ }^{2}$, E.N. Sarno ${ }^{1}$, S. Santos ${ }^{1}$, J.S. Spencer ${ }^{2}$, P.J. Brennan² and M.C.V. Pessolani ${ }^{1}$

\author{
${ }^{1}$ Laboratório de $\mathrm{H}$ anseníase, Instituto $\mathrm{O}$ swaldo Cruz, Fundação O swaldo Cruz, \\ Rio de Janeiro, RJ, Brasil \\ ${ }^{2}$ Department of Microbiology, Colorado State University, Fort Collins, CO , USA
}

\section{Correspondence \\ M.C.V. Pessolani \\ Laboratório de Hanseníase \\ Instituto O swaldo Cruz, FIOCRUZ \\ Av. Brasil, 4365 \\ 21045-000 Rio de Janeiro, RJ \\ Brasil \\ Fax: + 55-21-270-9997 \\ E-mail: cferrer@gene.dbbm.fiocruz.br \\ Presented at \\ SIMEC 2000 - International \\ Symposium on Extracellular \\ Matrix, Angra dos Reis, RJ, \\ Brazil, September 24-27, 2000. \\ Research supported by a PAPES 2 grant from the $\mathrm{O}$ swaldo $\mathrm{Cruz}$ \\ Foundation, Rio de Janeiro, RJ, \\ Brazil, and by contract NOI Al \\ 55262 from the National Institute \\ of Allergy and Infectious Diseases, \\ National Institutes of Health, USA.}

Received November 27, 2000

Accepted February 6, 2001

\section{Abstract}

It has been demonstrated that the $\alpha 2$ chain of laminin- 2 present on the surface of Schwann cells is involved in the process of attachment of Mycobacterium leprae to these cells. Searching for M. leprae lamininbinding molecules, in a previous study we isolated and characterized the cationic proteins histone-like protein (Hlp) and ribosomal proteins S4 and S5 as potential adhesins involved in M. leprae-Schwann cell interaction. Hlp was shown to bind $\alpha 2$-laminins and to greatly enhance the attachment of mycobacteria to ST88-14 Schwann cells. In the present study, we investigated the laminin-binding capacity of the ribosomal proteins S4 and S5. The genes coding for these proteins were PCR amplified and their recombinant products were shown to bind $\alpha 2$-laminins in overlay assays. However, when tested in ELISAbased assays and in adhesion assays with ST88-14 cells, in contrast to Hlp, S4 and S5 failed to bind laminin and act as adhesins. The lamininbinding property and adhesin capacity of two basic host-derived proteins were also tested, and only histones, but not cytochrome $c$, were able to increase bacterial attachment to ST88-14 cells. Our data suggest that the alanine/lysine-rich sequences shared by Hlp and eukaryotic H1 histones might be involved in the binding of these cationic proteins to laminin.

\section{Introduction}

Mycobacterium leprae peripheral nerve tropism leads to disabilities and deformities observed in over $25 \%$ of individuals affected with leprosy (1). In the nerves, the leprosy bacillus is essentially found inside Schwann cells that seem to constitute perfect niches in which this pathogen can survive and replicate (2). The molecular basis of nerve pathogenesis in leprosy continues to be poorly understood. Therefore, there is an urgent

\section{Key words}

- Mycobacterium leprae

- Laminin

- Adhesion

- Schwann cell

- Ribosomal protein

- Histone need in leprosy research to investigate the molecular mechanisms involved in M. lepraeSchwann cell interaction, which would necessarily include the effects of $M$. leprae invasion on the physiology and metabolism of Schwann cells and the ways in which these effects might be related to the progressive and irreversible degenerative process within peripheral nerves. A better understanding of this interaction would inevitable lead to the development and testing of new strategies for the therapy and prevention of nerve damage. 
A critical event in the process of Schwann cell invasion by $M$. leprae is the attachment of the bacteria to the cell surface. A recent study (3) showed that this step is essentially dependent on laminin-2 molecules present in the basal lamina that covers Schwann cells (4). Moreover, it was demonstrated that bacterial adherence was mediated by the globular domain of the $\alpha 2$ chain of the laminin-2 molecule (3) and that the membrane laminin receptor $\alpha$-dystroglycan serves as a Schwann cell receptor for M. leprae (5). The binding of laminin-2 to mycobacteria was then analyzed in more detail and the identification, cloning and expression of a lamininbinding protein from $M$. leprae was described (6). This protein, designated ML-LBP21, was demonstrated to avidly bind the recombinant globular domain of the $\alpha 2$ chaincontaining laminins and to be abundantly present on the bacterial surface. Moreover, recombinant ML-LBP21 was able to promote the binding and internalization of polystyrene beads into primary Schwann cells, suggesting a role for this protein as adhesin in the process of $M$. leprae nerve colonization in vivo.

In a recent report, we isolated, cloned and characterized a laminin-binding protein from the M. leprae cell wall (7). This protein was identified as a $21-\mathrm{kDa}$ histone-like protein (Hlp), a highly conserved cationic protein present in other species of mycobacteria. Sequence alignments revealed that Hlp is identical to the ML-LBP21 laminin-binding protein previously described (6). However, we showed that mutation in the $h l p$ gene was unable to affect the capacity of mycobacteria to bind to ST88-14 Schwann cells, suggesting that alternative adhesins and/or pathways might be used by mycobacteria during the process of adherence to these cells.

In our previous study, two other cationic proteins, the S4 and S5 ribosomal proteins, were isolated from the $M$. leprae cell wall and identified as potential laminin-binding adhesins (7). In the present study, these proteins were cloned and expressed in Escherichia coli and, together with the host basic proteins cytochrome $c$ and histones, were evaluated for their capacity to bind laminin and to act as adhesins. The observation that only histone-related proteins were able to enhance $M$. leprae attachment to Schwann cells suggests that common sequences and/ or structural features shared by these proteins might be directly involved in their binding to laminin.

\section{Material and Methods}

\section{Reagents}

Human merosin (a mixture of the $\alpha 2$ containing laminins [isoforms -2 and 4]) was purchased from Gibco BRL (Rockville, MD, USA). Histones from calf thymus and cytochrome $c$ were obtained from Sigma Chemical Co. (St. Louis, MO, USA). $\alpha 2$-Laminins were labeled with biotin using the FluoReporter Mini-biotin XX protein-labeling kit (Molecular Probes, Eugene, OR, USA) according to manufacturer instructions.

\section{M. leprae and Schwann cells}

M. leprae was purified from livers and spleens of infected armadillos as previously described (8). The ST88-14 schwannoma cell line was isolated from a patient with neurofibromatosis type I (9) and kindly donated by Prof. Jonathan Fletcher, Harvard University, Boston. The cells have been maintained in RPMI medium (Gibco BRL) supplemented with $15 \%$ fetal calf serum, $100 \mathrm{U} / \mathrm{ml}$ penicillin, $100 \mu \mathrm{g} / \mathrm{ml}$ streptomycin and $2 \mathrm{mM}$ L-glutamine in an incubator at $37^{\circ} \mathrm{C}$ with $5 \% \mathrm{CO}_{2}$.

\section{PCR and cloning}

The primers for the $s 5$ gene were constructed to correspond to the $5^{\prime}$ and 3 ' ends of 
the open reading frame previously identified as $M$. leprae $s 5$. The primers to amplify $s 4$ were designed based on the reported nucleotide sequence of the M. tuberculosis $s 4$ open reading frame, since the sequence of the corresponding $M$. leprae gene was not available at that time. The sequence of 5' primers for $s 4$ and $s 5$ were 5'-GAGACCATGGCTC GTTACACCGGAC-3' and 5'-GCTACCA TGGCGGCGCAGTCAGC-3', respectively. The 3' primers were 5'-GGGCTTGAGT AGTACTCGACGATCAG-3' and 5'-CCCT GCCTGTTCCCTCACGCGCC-3', respectively. The 5 ' primers of $s 4$ and $s 5$ incorporate $\mathrm{NcoI}$ sites for cloning into the $E$. coli expression vector pTYB4 (New England Biolabs Inc., Beverly, MA, USA).

The genes were PCR amplified from $M$. leprae genomic DNA with Vent DNA polymerase. The touchdown PCR method was used in a Perkin Elmer Geneamp PCR System 2400 at an initial annealing temperature of $64^{\circ} \mathrm{C}$ with a $1^{\circ} \mathrm{C}$ decrease for the first 10 cycles followed by 25 more cycles at $54^{\circ} \mathrm{C}$ annealing temperature. PCR products were gel purified and digested with the respective restriction enzymes and followed by ligation with NcoI- and SmaI-digested pTYB4. Ligation products were transformed into electrocompetent $E$. coli $\mathrm{DH} 5 \alpha$ cells. The sequences of the cloned $s 4$ and $s 5$ genes were confirmed by automated nucleotide sequencing (ABI; model 377).

\section{O verexpression and purification of S4 and S5 proteins}

Overexpression and purification of the M. leprae $\mathrm{S} 4$ and $\mathrm{S} 5$ proteins were performed according to the manufacturer's instruction manual for the IMPACT T7 onestep protein purification system. Briefly, $E$. coli ER2566 (New England Biolabs) harboring the plasmid constructs was grown up to an $\mathrm{OD}_{600} 0.5$ in ampicillin-containing LuriaBertani medium. IPTG was added to a final concentration of $500 \mu \mathrm{M}$ and grown at room temperature for another $3 \mathrm{~h}$. Cells were harvested and stored at $-80^{\circ} \mathrm{C}$. For purification, cells were resuspended in $50 \mathrm{mM}$ Tris- $\mathrm{HCl}$, pH 8.0, containing $0.5 \mathrm{M} \mathrm{NaCl}, 0.5 \mathrm{mM}$ EDTA and $0.5 \%$ CHAPS (buffer A) and disrupted by sonication on ice. Debris were removed by centrifugation at $15,000 \mathrm{~g}$ for 20 min and the supernatant was loaded on a chitin bead column pre-equilibrated with buffer A. Unbound proteins were removed by washing the column with 20 column volumes of buffer A. Finally, 4 column volumes of $50 \mathrm{mM}$ Tris- $\mathrm{HCl}, \mathrm{pH} 8.0$, containing 0.5 $\mathrm{M} \mathrm{NaCl}$ and $30 \mathrm{mM}$ DTT were passed through the column and left at $4^{\circ} \mathrm{C}$ for $72 \mathrm{~h}$ for cleavage. Proteins were eluted in $50 \mathrm{mM}$ Tris- $\mathrm{HCl}, \mathrm{pH}$ 8.0, and dialyzed against PBS (10 mM phosphate buffer, pH 7.2, 0.15 M $\mathrm{NaCl}$ ) with two changes at $4{ }^{\circ} \mathrm{C}$ to remove DTT. Purity of the fractions was checked by SDS-PAGE and protein concentration was measured with the Coomassie plus protein assay reagent (Pierce Chemical Company, Rockford, IL, USA) using BSA as standard.

\section{SD S-PAGE and laminin overlay assay}

Recombinant Hlp was obtained as previously described (7). Purified rHlp, rS4 and rS5 proteins $(0.5 \mu \mathrm{g} / \mathrm{ml})$ were loaded on each lane and SDS-PAGE was performed under reducing conditions in a $15 \%$ gel (10). Proteins were silver stained (11) or transferred onto nitrocellulose membranes and blots were blocked overnight with Tris-buffered saline containing $0.05 \%$ Tween 20 (TBS/ T) and $2 \%$ BSA. Membranes were incubated with biotin-labeled $\alpha 2$-laminins at $2.5 \mu \mathrm{g} / \mathrm{ml}$ in $\mathrm{TBS} / \mathrm{T}-1 \% \mathrm{BSA}$ for $3 \mathrm{~h}$ at $37^{\circ} \mathrm{C}$. Blots were washed with TBS/T and incubated with streptavidin peroxidase $(0.04 \mu \mathrm{g} / \mathrm{ml})$ in TBS/ $\mathrm{T}-1 \% \mathrm{BSA}$ for $30 \mathrm{~min}$ at room temperature. The reacting bands were developed with the chemiluminescent Supersignal Substrate (Pierce). The specificity of the reaction was assessed by omitting laminin in control membranes. 


\section{Laminin-binding ELISA-based assay}

To monitor the binding of soluble laminin to $\mathrm{rHlp}, \mathrm{rS} 4$ and $\mathrm{rS} 5,2.5 \mu \mathrm{g} / \mathrm{ml}$ of each protein in $0.1 \mathrm{M}$ carbonate buffer, $\mathrm{pH} 9.6$ (50 $\mu 1$ ), was used to coat the wells of polystyrene microplates (Corning, New York, NY, USA). Plates were incubated overnight at $4^{\circ} \mathrm{C}$. The wells were then washed with PBS and blocked for $2 \mathrm{~h}$ with $100 \mu \mathrm{l}$ PBS-2\% BSA at room temperature. Upon washing with PBS/ $0.05 \%$ Tween 20 (PBS/T), $50 \mu 1$ of different concentrations of biotinylated $\alpha 2$-laminins were added to the wells and incubation was performed at room temperature for $3 \mathrm{~h}$. The wells were rinsed with PBS/T and incubated with streptavidin-peroxidase (Pierce) at 0.5 $\mu \mathrm{g} / \mathrm{ml}$. Peroxidase activity was revealed with hydrogen peroxide and $O$-phenylenediamine. The reaction was stopped with $\mathrm{HCl}$ and read at $490 \mathrm{~nm}$ in a TitertekPlus microplate reader (ICN Biomedicals, Inc., Costa Mesa, CA, USA). In control wells, laminin was omitted and specific laminin binding was determined by subtracting the absorbance resulting from nonspecific binding detected in the control wells. Additionally, control wells coated with BSA were included in all binding assays. In parallel, wells coated with the proteins and blocked with $2 \%$ BSA were incubated with mouse polyclonal antibodies (1:500 in PBS/ T) for $2 \mathrm{~h}$ at room temperature. The wells were rinsed with PBS/T and incubated with goat anti-mouse IgG-peroxidase (Sigma) for $1 \mathrm{~h}$ at room temperature. Peroxidase activity was developed and read as mentioned above.

\section{In vitro adherence assays}

ST88-14 cells $\left(7 \times 10^{4}\right.$ cells $\left./ \mathrm{ml}\right)$ were plated onto 24 -well plates containing glass coverslips. After $24 \mathrm{~h}$ of incubation, the culture was washed three times with a solution of $25 \mathrm{mM}$ Tris-HCl, $\mathrm{pH} 7.4,5 \mathrm{mM}$ $\mathrm{CaCl}_{2}, 0.15 \mathrm{M} \mathrm{NaCl}$ (buffer B) and blocked with $1 \%$ BSA in buffer $\mathrm{B}$ for $1 \mathrm{~h}$ at $37^{\circ} \mathrm{C}$. FITC-labeled mycobacteria were prepared as described (12) and pretreated with B/BSA buffer containing or not each of the recombinant Hlp, S4, S5 proteins, cytochrome $c$ or histones for $1 \mathrm{~h}$ at $37^{\circ} \mathrm{C}$. The bacteria were added at a multiplicity of infection of 50:1. After incubation for $1 \mathrm{~h}$ at $37^{\circ} \mathrm{C}$, cells were washed at least six times with buffer B, stained with $50 \mu \mathrm{g} / \mathrm{ml}$ ethidium bromide for $10 \mathrm{~min}$, and fixed briefly with cold methanol. The number of bacteria attached to 100 cells was counted by fluorescence microscopy (Optiphot-2 Nikon, Tokyo, Japan).

\section{Antibodies to M. leprae recombinant proteins}

To prepare specific antibodies to Hlp and S5, 6-12-week old female BALB/c mice were injected subcutaneously at two sites in the abdomen with 20-40 $\mu \mathrm{g}$ of the proteins in an emulsion with incomplete Freund's adjuvant ( $0.2 \mathrm{ml}$ per mouse) and boosted 15 days later. Five days later, serum was examined for antibodies to Hlp and S5 by immunoblotting. The mice were boosted again and bled after 10 days.

\section{Results and Discussion}

In a previous study, laminin overlay assays with $M$. leprae cell wall allowed the identification of a single $25-\mathrm{kDa}$ band (7). This band was excised from the gel and subjected to in-gel proteolytic digestion with trypsin. The peptides were then analyzed by mass spectrometry (LC-MS-MS) and were found to map with 8 of the gene products recently defined by the $M$. leprae genome project. Since the laminin-binding proteins were never detected by conventional 2-D gel electrophoresis, Hlp and two other proteins, the S4 and S5 ribosomal proteins, were selected as potential laminin-binding proteins based on their extreme pI. Hlp was shown to bind $\alpha 2$-laminins and to greatly enhance the attachment of mycobacteria to ST88-14 Schwann cells (7). In the present study we 
investigated the laminin-binding capacity of the other two proteins, the ribosomal proteins S4 and S5.

To analyze the laminin-binding capacity of S4 and S5, the coding regions of their genes were successfully amplified by PCR from $M$. leprae genomic DNA according to the primers and conditions described in the Material and Methods section. The amplified fragments were purified from a $1.0 \%$ agarose gel, appropriately digested with restriction enzymes, and cloned into the pTYB4 vector of the IMPACT T7 expression system. The recombinant plasmids were used to transform E. coli ER2566 cells for expression. The recombinant S4 and S5 proteins were purified from crude extracts of induced cells by binding the fusion protein to a chitin affinity column followed by the release of the target protein from the column by inteinmediated self-cleavage. The purified proteins were analyzed by silver-stained SDS$15 \%$ PAGE showing single bands of 25 and $26 \mathrm{kDa}$ corresponding to S4 and S5, respectively (Figure 1A). The discrepancy between the calculated molecular mass of S4 and S5 (23.5 and $22.6 \mathrm{kDa}$, respectively) and that estimated by SDS-PAGE is most probably due to the highly basic nature of these proteins, which results in aberrant migration during electrophoresis (13). To analyze the laminin-binding capacity of the recombinant products, proteins were transferred onto a nitrocellulose membrane and probed with biotinylated $\alpha 2$ chain-containing laminins. Figure 1B shows that, similarly to rHlp, rS4 and rS5 bind laminins. Since Hlp, S4 and S5 share the property of being cationic proteins, these results suggest that they were binding to laminin by nonspecific electrostatic interactions.

The recombinant $\mathrm{S} 4$ and $\mathrm{S} 5$ were tested in two additional assays to evaluate their capacity to bind $\alpha 2$-laminins and act as adhesins. Initially, using an ELISA-based assay, the recombinant proteins were immobilized in wells of microtiter plates and the binding of soluble biotinylated $\alpha 2$-laminins was assessed with the streptavidin peroxidase complex. Soluble biotinylated $\alpha 2-$ laminins bound to Hlp in a dose-dependent manner, reaching a plateau at a concentration of $2.5 \mu \mathrm{g} / \mathrm{ml}$ (Figure $2 \mathrm{~A}$ ). In contrast, $\mathrm{S} 4$ and S5 were unable to bind $\alpha 2$-laminins even at laminin concentrations of $5 \mu \mathrm{g} / \mathrm{ml}$. To rule out the possibility that the results obtained could be the consequence of a lower efficiency of the S4 and S5 proteins to bind to microtiter wells, some wells coated with Hlp and S5 were developed with specific polyclonal antibodies produced against these proteins. As shown in the inset of Figure 2A, equivalent amounts of these proteins seem

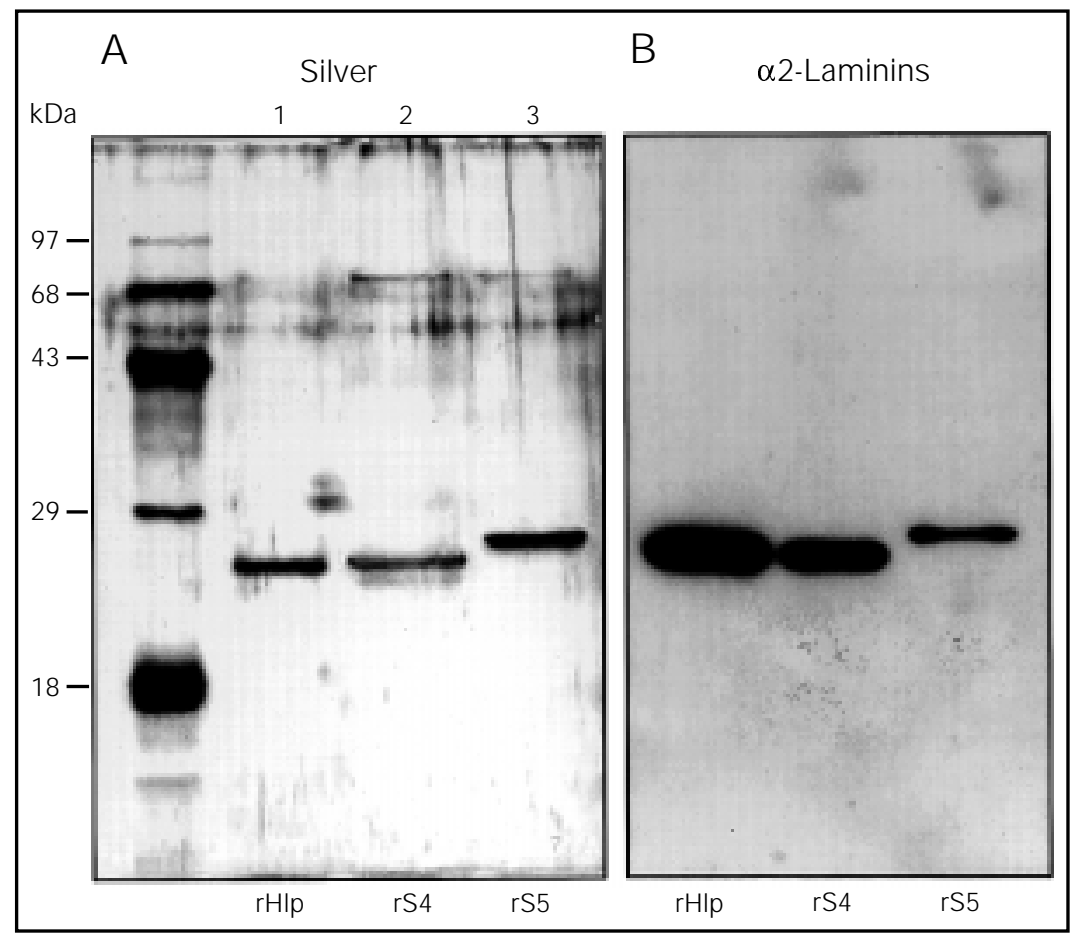

Figure 1 - Expression and laminin-binding capacity of M. leprae S4 and S5. The coding regions of the $s 4$ and $s 5$ genes were amplified by PCR and cloned into PTYB4 and the recombinant plasmids were used to transform E. coli ER2566 cells. The recombinant proteins were purified from crude extracts of induced cells by binding the fusion protein to a chitin affinity column followed by the release of the target protein from the column by intein-mediated self-cleavage. A, The purified rHIp (lane 1), rS4 (lane 2) and rS5 (lane 3) were analyzed by SDS-15\% PAGE with silver staining. B, Binding of $\alpha 2$-laminins to $\mathrm{rHlp}, \mathrm{rS} 4$ and S5. Proteins were separated by SDS-15\% PAGE and transferred to a nitrocellulose membrane. Nitrocellulose transfers were overlayed with $2.5 \mu \mathrm{g} / \mathrm{ml}$ biotinylated laminin and developed with the streptavidin peroxidase complex using an enhanced chemiluminescence substrate. Molecular mass markers are indicated on the left. 


\section{A}

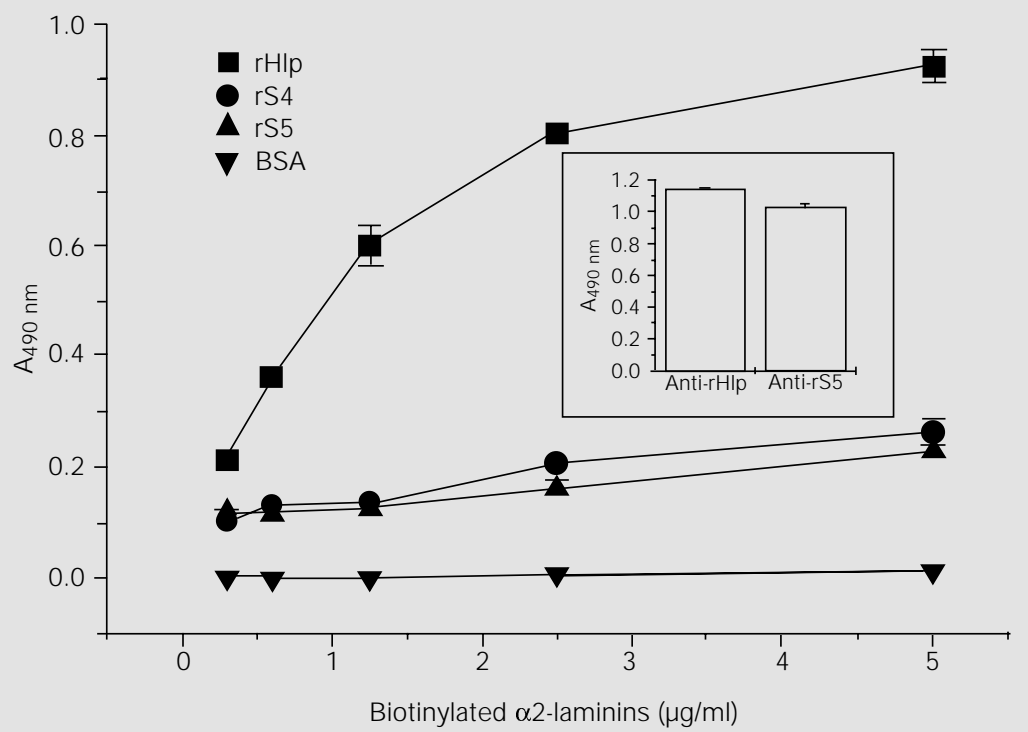

B

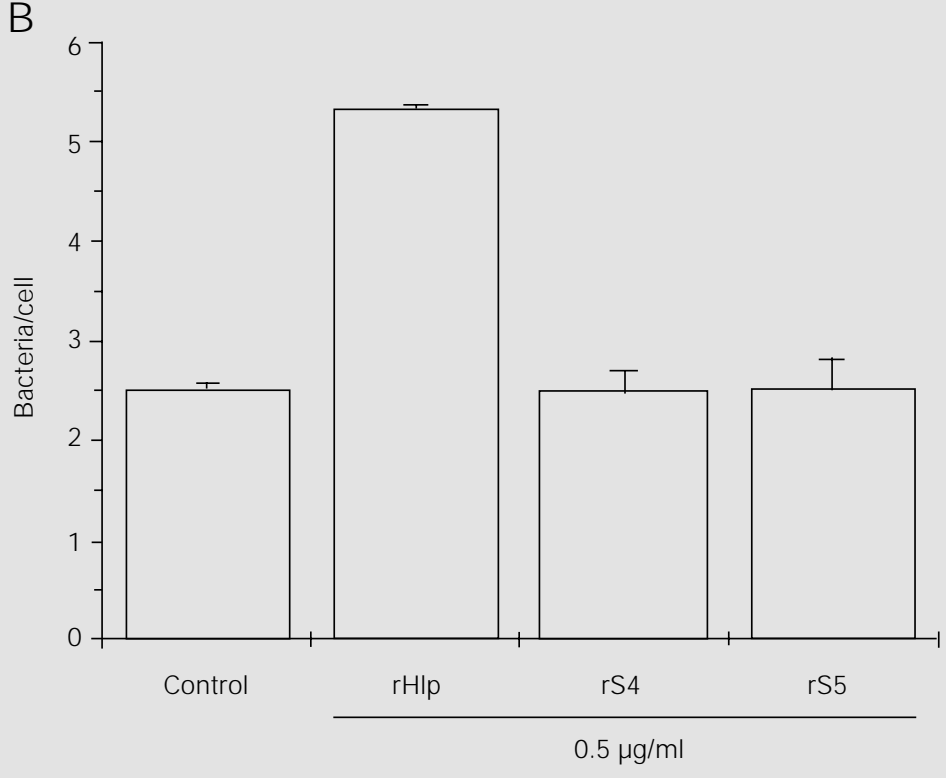

Figure 2 - A, Laminin-binding capacity of M. leprae S4 and S5 analyzed by ELISA. Microtiter wells coated with $\mathrm{M}$. leprae rHlp, $\mathrm{rS4}$, rS5 and BSA were incubated with different concentrations of biotinylated $\alpha 2$-laminins. In the inset, microtiter wells coated with $\mathrm{M}$. leprae rHlp and rS5 were incubated with mouse polyclonal antibodies (1:500) anti-rHIp and anti-rS5, respectively. Binding is expressed as absorbance units at $490 \mathrm{~nm}$. Data represent the mean \pm SEM of five experiments carried out in triplicate. B, Recombinant Hlp but not S4 and S5 enhanced M. leprae adherence to Schwann cells. Recombinant Hlp, S4 and S5 were purified from a bacterial extract of the recombinant clone using the IMPACT system. ST8814 cells were cultivated on 24-well tissue culture plates and incubated with FITC-labeled M. leprae pretreated with $0.5 \mu \mathrm{g} / \mathrm{ml}$ of rHlp, rS4 and rS5. After $1 \mathrm{~h}$ of incubation, unbound bacteria were removed by washing and cells were stained with ethidium bromide and analyzed under a fluorescence microscope. Results are reported as the average number of bacteria per cell. Data represent the mean \pm SD of a typical experiment carried out in duplicate. Five experiments were performed with similar results. to be present in the wells.

To investigate whether S4 and S5 can mediate $M$. leprae adherence to Schwann cells, they were compared with Hlp for their ability to affect bacterial attachment to the ST88-14 human schwannoma cell line. Bacteria were labeled with FITC and pre-incubated with the recombinant proteins for $1 \mathrm{~h}$ prior to adding the mixture to confluent cultures of ST88-14. In agreement with the ELISA-based assay, Figure 2B shows that, in contrast to Hlp, S4 and S5 failed to enhance $M$. leprae binding to ST88-14 cells. These results can be at least partially explained by the differences in the conformational states of these proteins in these assays. While in the ELISA-based assay and in the cell adhesion assay the native conformation of these proteins was preserved, overlay assays were always run under denatured conditions. Thus, it seems that S4 and S5 bind laminin only in their denatured forms, but not in their native conformation. These results contradicted our initial hypothesis that the binding of these cationic proteins to $\alpha 2$ laminins would be mediated by nonspecific electrostatic interactions.

To better understand the laminin-binding property of Hlp, testing was done to ascertain whether two basic proteins also bind laminins and can act as adhesins. One of them, a mixture of calf thymus histones containing histone $\mathrm{H} 1$, shares sequence homology with Hlp at the C-terminal region of the protein. The other one, cytochrome $c$, was a protein not related to Hlp. Figure 3A shows that both histones as well as cytochrome $c$ were able to bind laminin in overlay assays, similarly to Hlp, S4 and S5. However, interestingly, only histones, but not cytochrome $c$, were able to increase bacterial attachment to ST88-14 cells to the levels obtained when the same assay was performed with purified rHlp (Figure 3B).

Mycobacterial Hlp correspond to typical DNA binding proteins and have recently been found to bind DNA in vitro (14). How- 
ever, they have a unique structure sharing sequence and structural similarities with both prokaryotic Hlp and eukaryotic class $\mathrm{H} 1$ histones. Mycobacterial Hlp are about twice the size of other bacterial Hlp. The N-terminal half of M. leprae Hlp shares 49.4 and $55.1 \%$ identity with $\mathrm{HU}$ from $E$. coli and $\mathrm{Hb}$ from Bacillus subtilis, respectively. The second half of mycobacterial Hlp has an unusual amino acid composition owing to a high alanine and lysine content (22 and 18.5\% for $M$. leprae Hlp, respectively), resembling in this way the $\mathrm{C}$-terminal region of eukaryotic class H1 histones. This abundance in alanine and lysine favors the formation of expanded $\alpha$-helix chains in M. leprae Hlp as predicted by the Plotstructure software of the Genetics Computer Group software package (data not shown) that are also present in H1 histones.

In conclusion, we have shown that the $M$. leprae ribosomal proteins $\mathrm{S} 4$ and $\mathrm{S} 5$ were unable to act as adhesins in the context of $M$. leprae-ST88-14 Schwann cell interaction. On the other hand, the observation that only histone-related proteins were able to enhance M. leprae attachment to Schwann cells suggests that common sequences and/or structural features shared by these proteins might be directly involved in their binding to laminin. Therefore, we hypothesize that the alanine/lysine-rich sequences shared by Hlp and $\mathrm{H} 1$ histones might be involved in the binding of these proteins to laminin and in their capacity to act as adhesins. Currently, truncated Hlp molecules corresponding to the $\mathrm{C}$-terminal and $\mathrm{N}$-terminal regions of the protein are being produced to test this hypothesis.

\section{References}

1. WHO (1998). Elimination of leprosy as a public health problem (update). Weekly Epidemiological Record, 73: 308-312.

2. Antia NH (1982). Leprosy - a disease of the Schwann cell. Leprosy in India, 54: 599-603.

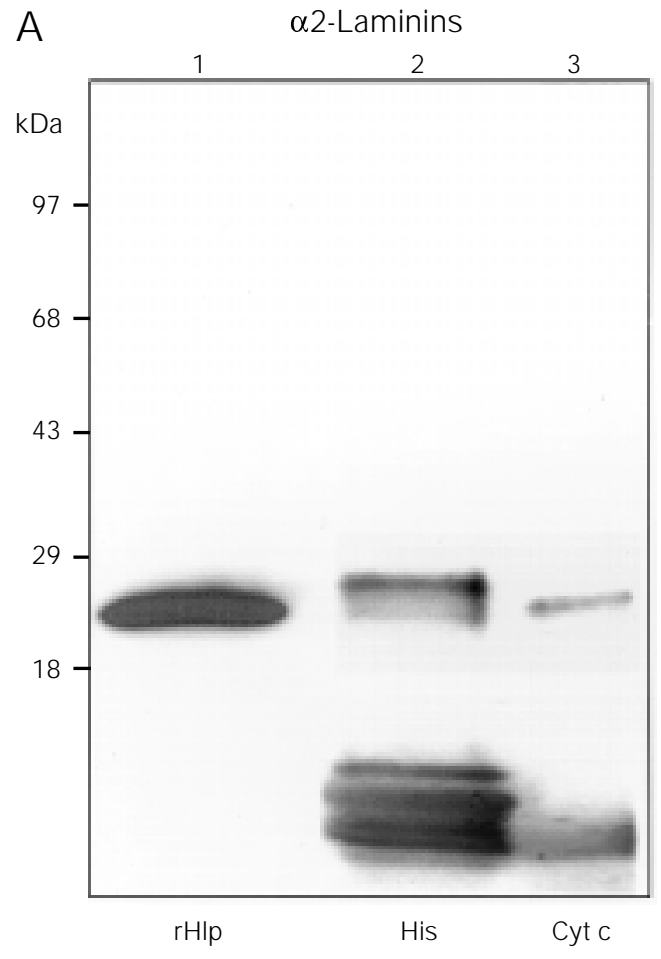

Figure 3 - Histone-related proteins enhanced $M$. leprae adherence to Schwann cells. A, rHlp (0.5 $\mu \mathrm{g}$; lane 1), histones (His, 1 $\mu \mathrm{g}$; lane 2) and cytochrome c (Cyt C, $1 \mu \mathrm{g}$; lane 3) were fractionated by SDS-PAGE and proteins were transferred to nitrocellulose membranes. Blots were incubated with $2.5 \mu \mathrm{g} / \mathrm{ml}$ of biotinylated $\alpha 2$-laminins and developed with the streptavidin peroxidase complex using an enhanced chemiluminescence substrate. In control blots laminin was omitted. Molecular mass markers are indicated in $\mathrm{kDa}$ on the left. B, FICT-labeled $M$. leprae was pre-incubated with $2.5 \mu \mathrm{g} / \mathrm{ml}$ and $100 \mu \mathrm{g} / \mathrm{ml}$ Cyt c, $2.5 \mu \mathrm{g} / \mathrm{ml} \mathrm{M}$. leprae $\mathrm{rH} / \mathrm{p}$ and $2.5 \mu \mathrm{g} / \mathrm{ml}$ His. The number of bacteria bound to the cells was counted by fluorescence microscopy. Data represent the mean \pm SD of a typical experiment carried out in duplicate. Two experiments were performed with similar results.

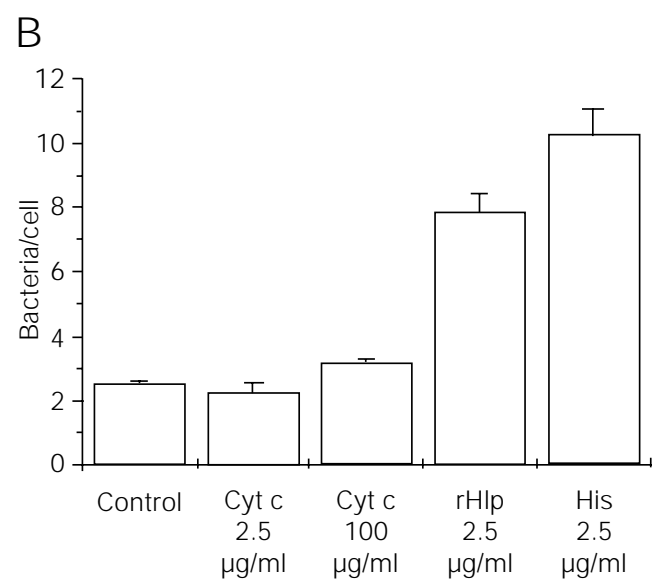

3. Rambukkana A, Salzer J L, Yurchenco PD \& Tuomanen EI (1997). Neural targeting of Mycobacterium leprae mediated by the $\mathrm{G}$ domain of the laminin-alpha2 chain. Cell, 88: 811-821.

4. Leivo I \& Engvall E (1988). Merosin, a protein specific for basement membranes of Schwann cells, striated muscle, and trophoblast, is expressed late in nerve muscle development. Proceedings of the National Academy of Sciences, USA, 85: 1544-1548. 
5. Rambukkana A, Yamada H, Zanazzi G, Mathus T, Salzer J L, Yurchenco PD, Campbell KP \& Fischetti VA (1998). Role of alpha-dystroglycan as a Schwann cell receptor for Mycobacterium leprae. Science, 282: 2076-2079.

6. Shimoji $Y, \mathrm{Ng} V$, Matsumura $\mathrm{K}$, Fischetti VA \& Rambukkana A (1999). A 21-kDa surface protein of Mycobacterium leprae binds peripheral nerve laminin-2 and mediates Schwann cell invasion. Proceedings of the National Academy of Sciences, USA, 96: 9857-9862.

7. Marques MAM, Mahapatra S, Nandan D, Dick T, Sarno EN \& Pessolani MCV (2000). Bacterial and host-derived cationic proteins bind $\alpha 2$-laminins and enhance $\mathrm{My}$ cobacterium leprae attachment to human Schwann cells. Microbes and Infection, 2: 1407-1417.
8. Draper $P$ (1980). Purification of $M$. leprae. Annex 4 of the Report of the Fifth Meeting of the Scientific Working Group on the Immunology of Leprosy (IMMLEP), Geneva, 24-26 J une 1980, WHO document TDR/IM MLEP-SWG (5)/80.3, World Health Organization, Geneva.

9. Fletcher JA, Kozakewich HP, Hoffer HA, Lage J M, Weidner N, Tepper R, Pinkus GS, Morton CC \& Corson J M (1991). Diagnostic relevance of clonal cytogenetic aberrations in malignant soft tissue tumors. New England J ournal of Medicine, 324: 436-442.

10. Laemmli UK (1970). Cleavage of structural protein during the assembly of the head of bacteriophage T4. Nature, 227: 680-685.

11. Morrissey J H (1981). Silver stain for proteins in polyacrylamide gels: a modified procedure with enhanced uniform sensitivity. Analytical Biochemistry, 117: 307310.

12. Drevets DA \& Campbell PA (1991). Macrophage phagocytosis: use of fluorescence microscopy to distinguish between extracellular and intracellular bacteria. J ournal of Immunological Methods, 142: 31-38.

13. Panyim S \& Chalkley R (1971). The molecular weights of vertebrate histones exploiting a modified sodium dodecyl sulphate electrophoretic method. J ournal of Biological Chemistry, 246: 7557-7560.

14. Matsumoto $S$, Yukitake $H$, Furugen $M$, Matsuo T, Mineta T \& Yamada T (1999). Identification of novel DNA-binding protein from Mycobacterium bovis bacillus Calmette-Guérin. Microbiology and Immunology, 43: 1027-1036. 